\section{(6) OPEN ACCESS}

\title{
Autologous internal limiting membrane flap for retinal detachment due to posterior retinal tears over choroidal atrophy in highly myopic eyes
}

\author{
Tommaso Rossi, ${ }^{1,2}$ Tomaso Caporossi, Stanislao Rizzo, ${ }^{2}$ Carlandrea Trillo, ${ }^{1}$ \\ Serena Telani, ${ }^{1}$ Francesco Barca, ${ }^{2}$ Guido Ripandelli ${ }^{3}$
}

\begin{abstract}
- Additional material is published online only. To view please visit the journal online (http://dx.doi.org/10.1136/ bjophthalmol-2018-313099).

${ }^{1}$ Department of Ophthalmology, IRCCS Ospedale Policlinico San Martino, Genoa, Italy ${ }^{2}$ Department of Ophthalmology, Ospedale Careggi, Firenze, Italy ${ }^{3}$ IRCCS G.B. Bietti Foundation ONLUS, Roma, Italy
\end{abstract}

Correspondence to Tommaso Rossi, IRCCS Ospedale Policlinico San Martino, Genoa 16100, Italy; tommaso.rossi@ usa.net

Received 22 August 2018 Revised 28 September 2018 Accepted 29 September 2018 Published Online First 15 October 2018
Check for updates

(C) Author(s) (or their employer(s)) 2019. Re-use permitted under CC BY-NC. No commercial re-use. See rights and permissions. Published by BMJ.

To cite: Rossi T, Caporossi T, Rizzo S, et al. Br J Ophthalmol 2019;103:1133-1136.

\begin{abstract}
Purpose To review a series of highly myopic eyes with retinal detachment undergoing pars plana vitrectomy with autologous internal limiting membrane (ILM) flap placed over posterior retinal breaks located in areas of choroidal atrophy.
\end{abstract}

Methods Retrospective review of 13 consecutive patients receiving pars plana vitrectomy with ILM flap over causative breaks, compared with 19 controls receiving the same surgery with ILM peeling but no ILM flap. Main outcome measures included anatomical success rate, visual acuity, number of surgeries and the rate of silicone oil removal.

Results Patients in the ILM group required $2.08 \pm 0.37$ interventions versus $2.58 \pm 0.75$ in the control group $(p=0.037)$. One $(1 / 13 ; 7.6 \%)$ patient in the ILM group required additional unplanned surgery versus $8 / 19(42.10 \%)$ in the control group $(p=0.038)$. Final anatomical success rate defined as attached retina after silicone oil (SiO) removal was 13/13 in the I-ILM group and $14 / 19(73.6 \%)$ in the control group $(p=0.052)$. No patients $(0 / 13)$ in the I-ILM group retained SiO at the end of follow-up versus $4 / 19(21.1 \%)$ patients in the control group ( $p=0.061)$. Best-corrected visual acuity at the end of follow-up was logMAR 0.65 \pm 0.36 (20/91 Snellen) in the ILM group and logMAR 0.89 \pm 0.44 (20/158 Snellen) in the control group $(p=0.20)$.

Conclusion Autologous ILM may help seal posterior retinal breaks and improve the surgical prognosis of retinal detachment due to breaks located over areas of choroidal atrophy within the myopic staphyloma.

\section{INTRODUCTION}

Retinal detachment (RD) is a well-known complication of pathological myopia ${ }^{1}$ whose surgical treatment can be particularly challenging, especially when retinal tears arise within the staphyloma, over areas of retinal pigment epithelium (RPE) disturbance and/or overt choroidal atrophy.

Proposed treatments include pars plana vitrectomy (PPV) with gas or silicone oil (SiO) tamponade, ${ }^{2}$ scleral buckling alone ${ }^{34}$ or associated to $\mathrm{PPV}^{5}$ and internal limiting membrane (ILM) peeling with varying success. ${ }^{6}$ Regardless of surgical approach, RDs due to posterior tears located over atrophic choroid retain a higher re-detachment rate and dismal prognosis ${ }^{7}$ due to the intrinsic re-attachment difficulty and reduced retinal adherence over areas where very little or no RPE and choriocapillaris are present.
Recently, Rizzo et $a l^{8}$ placed autologous ILM over posterior retinal tears arising within the staphyloma and over areas of choroidal atrophy in highly myopic RDs. Kumase et $a l^{9}$ proposed a similar technique for perifoveal macular holes and Okuda et al described a single similar case of highly myopic RD associated to macular hole. ${ }^{10}$

The purpose of the present paper is to report a series of highly myopic eyes with RD due to tears located over areas of choroidal atrophy within the staphyloma or around the optic nerve (parapapillary), treated by means of PPV and autologous ILM flap transplantation over the causative retinal tear. In order to evaluate if the use of autologous ILM in terms of prognosis and/or risk of re-detachment, we compared results with the standard of care, represented by PPV, laser treatment and SiO tamponade and ILM peeling alone.

\section{MATERIALS AND METHODS}

We retrospectively reviewed the charts of all patients undergoing PPV for RD in highly myopic eyes (more myopic than $-9 \mathrm{D}$ ) with posterior staphyloma, operated on between 1 May 2015 and 1 November 2017 associated to retinal tears and/ or holes within the vascular arcades. We excluded patients with macular holes, incomplete charts and/ or follow-up less than 6 months of duration, as well as four patients with multiple tears and three with a giant retinal tear.

Thirty-two patients satisfied inclusion criteria; 13/32 received autologous ILM transplantation over the causative tear in addition to standard vitrectomy (the ILM group) and 19/32 received the same surgery except no ILM was used (control Group).

All patients underwent a standard three-port $23 \mathrm{G}$ or $25 \mathrm{G}$ PPV, triamcinolone-assisted posterior vitreous detachment induction with meticulous removal of vitreous remnants over the retinal surface, fluid-gas exchange through the posterior break and $\mathrm{SiO}$ tamponade $(2000$ cs polydimethylsiloxane; Micromed, Rome, Italy). Patients in the control group underwent ILM peeling after brilliant blue G staining (Retindyne; Alfa Intes, Italy) while an autologous ILM flap (either hinged or free) was placed over the posterior retinal tear under perfluorocarbon liquid, after retinal reattachment, as elsewhere described ${ }^{8}$ (figure 1, online supplementary video 1 ).

Silicone oil was used as a long-acting tamponade in all cases in order to achieve a faster recovery and 


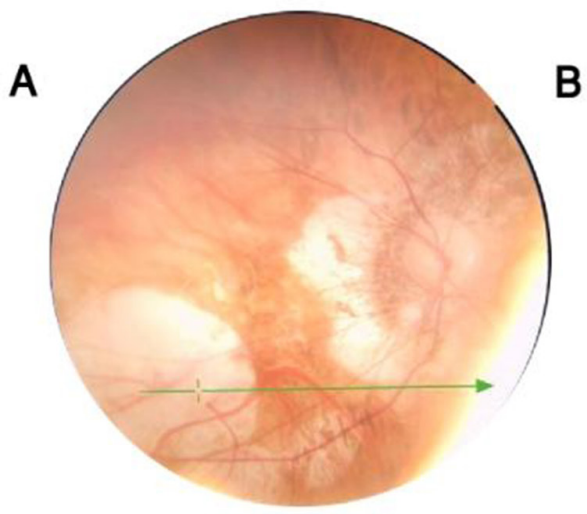

B

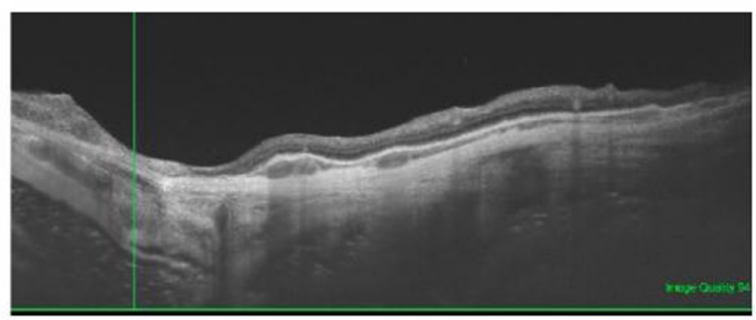

Figure 1 Postoperative retinography (A) and optical coherence tomography (OCT) (B) of patient 11. Green line in (A) shows OCT scan vector. Note that there is no full-thickness retina where autologous internal limiting membrane was placed intraoperatively, corresponding to the retinal pigment epithelium and choroidal atrophy window defect.

also because the sealing of retinal tears overlying areas of patchy choroidal atrophy is lengthy and difficult.

No laser treatment was directly applied around the causative retinal tear overlying choroidal atrophy because the lack of RPE jeopardises the rationale for laser use and increases the risk of overtreatment resulting in iatrogenic retinal tears. Additional prophylactic laser treatment over areas of retinal degeneration was occasionally applied as per the discretional advice of the surgeon.

Outcome measures included visual acuity, attachment rate, number of surgeries and proportion of patients retaining $\mathrm{SiO}$ at the end of follow-up.

Statistical analysis used analysis of variance and t-test for continuous variables and $\chi^{2}$ test or Fisher's exact test for non-parametric ones. P values equal or less than 0.05 have been considered statistically significant.

\section{RESULTS}

The two groups did not differ significantly at baseline for age, sex, refraction, axial length and follow-up (table 1). Vision at baseline was similar and extremely low in both groups since the macula was off in all cases.

The chance for a single patient of undergoing additional unplanned surgery (ie, any surgical procedure exceeding original surgery and $\mathrm{SiO}$ removal) was $1 / 13(7.6 \%)$ in the ILM group and $8 / 19(42.1 \%)$ in the control group $(p=0.038)$. The ILM group underwent and average $2.08 \pm 0.37$ interventions versus $2.58 \pm 0.75$ in the control group (table $2 ; \mathrm{p}=0.037$ ).

Initial anatomical success rate intended as attached retina 1 month after SiO removal was achieved in 12/13 (92.3\%) patients in the ILM group and $13 / 19(68.4 \%)$ in the control group $(p=0.085)$. Anatomical success rate at the end of follow-up was

Table 1 Demographics of control and internal limiting membrane (ILM) groups

\begin{tabular}{llll}
\hline & ILM group & Control group & P values \\
\hline No of patients & 13 & 19 & - \\
\hline Men, women $(\mathrm{n}, \%)$ & $7(53.8 \%), 6(47.2 \%)$ & $10(52.6 \%), 9(47.4 \%)$ & $\mathrm{ns}$ \\
\hline Age (years \pm SD) & $52.9 \pm 8.1$ & $55.4 \pm 6.2$ & $\mathrm{~ns}$ \\
\hline Axial length (mm) & $32.18 \pm 2.6$ & $31.09 \pm 2.3$ & $\mathrm{~ns}$ \\
\hline Myopic refraction (D \pm SD) & $12.95 \pm 2.73$ & $13.34 \pm 3.16$ & $\mathrm{~ns}$ \\
\hline Follow-up (months) & $13.2 \pm 2.92$ & $15.8 \pm 4.12$ & $\mathrm{~ns}$ \\
\hline
\end{tabular}

$\mathrm{ns}$, not significant.
$13 / 13(100 \%)$ in the I-ILM group and 14/19 (73.6\%) in the control group $(\mathrm{p}=0.052)$.

No patients $(0 / 13)$ in the ILM group retained $\mathrm{SiO}$ at the end of follow-up versus $4 / 19$ (21.1\%) patients in the control group $(\mathrm{p}=0.061)$.

Best-corrected visual acuity (BCVA) at the end of follow-up was $\log$ MAR $0.65 \pm 0.36$ (20/91 Snellen) in the ILM group and $\log$ MAR $0.89 \pm 0.44(20 / 158$ Snellen) in the control group $(\mathrm{p}=0.20)$, the difference being not significant.

\section{DISCUSSION}

Degenerative myopia causes profound changes of virtually all ocular structures involved in retinal adhesion. On the subretinal

Table 2 Number of procedures and reason for unplanned reinterventions within the ILM and control groups

\begin{tabular}{|c|c|c|c|c|}
\hline \multirow[b]{2}{*}{$\begin{array}{l}\text { Patient } \\
\text { number }\end{array}$} & \multicolumn{2}{|l|}{ ILM group } & \multicolumn{2}{|c|}{ Control group } \\
\hline & $\begin{array}{l}\text { Number of } \\
\text { procedures }\end{array}$ & Reason & $\begin{array}{l}\text { Number of } \\
\text { procedures }\end{array}$ & Reason \\
\hline 1 & 2 & & 2 & \\
\hline 2 & 2 & & 3 & Lysis of synechia \\
\hline 3 & 3 & RRD & 4 & RRD, SiO removal \\
\hline 4 & 2 & & 2 & \\
\hline 5 & 2 & & 2 & \\
\hline 6 & 2 & & 4 & RRD $\times 2$, Si0 retained \\
\hline 7 & 2 & & 4 & RRD, SiO removal \\
\hline 8 & 2 & & 2 & SiO retained \\
\hline 9 & 2 & & 2 & \\
\hline 10 & 2 & & 2 & \\
\hline 11 & 2 & & 2 & Si0 retained \\
\hline 12 & 2 & & 3 & RRD \\
\hline 13 & 2 & & 3 & ERM peeling \\
\hline 14 & & & 2 & \\
\hline 15 & & & 2 & \\
\hline 16 & & & 2 & \\
\hline 17 & & & 3 & RRD, SiO retained \\
\hline 18 & & & 2 & \\
\hline 19 & & & 3 & ERM peeling \\
\hline Mean & 2.08 & & 2.58 & \\
\hline SD & 0.37 & & 0.75 & \\
\hline
\end{tabular}

ERM, epi-retinal membrane; ILM, internal limiting membrane; RRD, recurrent retinal detachment; SiO, silicone oil. 
level concur the increased posterior scleral curvature, ${ }^{11}$ choroid thinning, choriocapillaris rarefaction and RPE atrophy. ${ }^{12}$ Increased vessel ${ }^{13}$ and ILM stiffness ${ }^{14}$ act from within the retinal structure while anomalous vitreoretinal adhesion and increased vitreous shear stress exert traction on the epiretinal side.

All named factors reduce retinal adherence and help explain why the posterior retina is both more prone to tear and detach and difficult to re-attach in highly myopic eyes.

Among the typical clinical findings of highly myopic RD is the presence of posterior retinal tears located within the staphyloma, often adjacent to retinal vessels or the optic nerve and overlying areas of choroidal atrophy. These breaks pose specific challenges: due to lack of contrast they are difficult to diagnose ${ }^{15}$ and harder to repair since physiological adherence mechanism related to RPE function and transretinal fluid dynamics are weaker and retinopexy scarcely efficient, if at all.

As of today, the countermeasures deployed to obtain retinal adherence in such cases aim at altering the scleral contour through scleral buckling ${ }^{3}{ }^{4}$ and/or at increasing tamponade duration using long-term, high-viscosity SiO. Both strategies frequently prove disappointing, falling short of their purpose, since the former is technically difficult and does not apply to peripapillar tears while the latter often only postpones re-detachment. On the other hand, retinopexy frequently adds little or no benefit, lacking its anatomical prerequisite: a healthy or at least viable RPE and choroid.

The rationale for using autologous ILM as a biologic sealant is as follows: whenever RPE and choriocapillaris atrophy compromise active transretinal fluid transportation and mechanisms of intercellular photoreceptor matrix adhesion, glueing or stuffing tissue defects may prevent subretinal fluid infiltration and progressive re-detachment. It seems therefore justified only (or mainly) in a subset of highly myopic RDs with retinal tears located over choroidal atrophy.

In our series of autologous ILM transplantation, we obtained a significantly higher success rate with less surgery than standard of care: only $1 / 13(7.6 \%)$ patient needed unplanned adjunctive surgery versus $8 / 19(42.1 \%)$ in the control group and $\mathrm{SiO}$ was successfully removed in all patients. This issue deserves further comment since the lack of underlying RPE and choroidal tissue is likely the main reason for re-detachment in highly myopic eyes, when tamponade is removed or gas absorbed. For this very reason, retinal attachment after $\mathrm{SiO}$ removal is probably the single more interesting outcome measure for this surgical series.

The ILM fragment may promote retinal tear sealing through a mechanism postulated by De Novelli et al $^{16}$ for macular holes $(\mathrm{MHs})$ in highly myopic eyes: the tissue acts as a guide for glial cells to slide and gap progressively the entire break span (see figure 1). The role of cryopexy or laser over such areas is negligible if not counterproductive, due to the lack of RPE and choriocapillaris. For these reasons, promoting sealing over the break by using autologous ILM instead of adhesion around it seems a viable alternative and retinal re-detachment rate after $\mathrm{SiO}$ removal confirms its value versus the adhesive inflammation process stimulated by the retinopexy, however applied.

The tentative use biologic sealants for retinal tears is a long one and includes several approaches with varying success. First attempts based on liquid adjuvants: blood, platelets ${ }^{17}$ and growth factors $^{18}$ were applied to MHs and later abandoned because of poor anatomical and functional results. It is possible that intraocular fluid lavage or dilution of biologic adjuvants prevented adequate concentration at wound site and therefore their efficacy.

The use of layered tissue for retinal wound closure started in 2010 when Michalewska described the use of an inverted
ILM flap over idiopathic MHs. The technique proved largely successful gaining acceptance and increased indications: larger ${ }^{19} 20$ and chronic idiopathic $\mathrm{MH}$, myopic $\mathrm{MH}^{21} 22$ and, lastly, posterior retinal tears. ${ }^{23}$ Other biologic sealants have also been advocated: Chen $e t \mathrm{al}^{24}$ placed the crystalline lens anterior capsule over $\mathrm{MHs}$ and more recently, full-thickness autologous retina has been used for $\mathrm{MHs}$ and retinal detachment. ${ }^{25}$ As of today, purported benefits of full-thickness retina compared with other techniques including autologous ILM cannot be established with certainty and the deliberate creation of a retinotomy in myopic retinal detachments is in our opinion bothersome and might worsen prognosis, increasing the risk of PVR and re-detachment.

All the above treatments based on 'solid' sealant (or better biologic layers of different nature) attained better success than previous 'liquid' ones, almost regardless of tissue origin and structure, suggesting the scaffold function is at least as important as their biologic properties, if not prominent.

The ILM flap group showed a trend towards better BCVA at the end of follow-up, although not statistically significant. This result may be underestimated as might be the overall success rate defined as retinal attachment after tamponade removal since a significant proportion of control eyes (some of which previously re-detached), retained tamponade.

In summary, the use of ILM as an autologous sealant for retinal tears located over patchy choroidal atrophy in myopic eyes represents a theoretically sound treatment with interesting preliminary results that appear as a significant step forward when compared with the standard of care.

This study suffers all typical limitations related to retrospective series, including the relatively limited number of cases, lack of randomisation and multiple surgeons. However, the occurrence of RD due to retinal tears located over choroidal atrophy is relatively uncommon and it is therefore difficult to gather larger series. On the other hand, the surgical technique was standardised and the presence of a control group based on previous standard of care of the same surgeons allows meaningful comparison.

Acknowledgements The authors wish to thank the Fondazione Roma for support. The work was completed at Careggi and Policlinico San Martino Hospitals.

Contributors TR: surgeon, designed the study, wrote the manuscript. TC: surgeon, revised the manuscript. SR: surgeon, wrote and revised the manuscipt. CT: analysed data, wrote the manuscipt. ST: analysed data, statistics and revised the manuscript. FB: wrote and revised the manuscript. GR: designed the study and wrote the manuscript.

Funding The authors have not declared a specific grant for this research from any funding agency in the public, commercial or not-for-profit sectors.

Competing interests None declared.

Patient consent Not required.

Ethics approval IRCCS Ospedale Policlinico San Martino

Provenance and peer review Not commissioned; externally peer reviewed.

Open access This is an open access article distributed in accordance with the Creative Commons Attribution Non Commercial (CC BY-NC 4.0) license, which permits others to distribute, remix, adapt, build upon this work non-commercially, and license their derivative works on different terms, provided the original work is properly cited, appropriate credit is given, any changes made indicated, and the use is non-commercial. See: http://creativecommons.org/licenses/by-nc/4.0/

\section{REFERENCES}

1 Baba T, Ohno-Matsui K, Futagami S, et al. Prevalence and characteristics of foveal retinal detachment without macular hole in high myopia. Am J Ophthalmol 2003;135:338-42. 
2 Heimann $\mathrm{H}$, Zou $\mathrm{X}$, Jandeck $\mathrm{C}$, et al. Primary vitrectomy for rhegmatogenous retinal detachment: an analysis of 512 cases. Graefes Arch Clin Exp Ophthalmol 2006;244:69-78.

3 Devin F, Tsui I, Morin B, et al. T-shaped scleral buckle for macular detachments in high myopes. Retina 2011;31:177-80.

4 Ripandelli G, Rossi T, Scarinci F, et al. Encircling scleral buckling with inferior indentation for recurrent retinal detachment in highly myopic eyes. Retina 2015:35:416-22.

5 Nishimura A, Kimura M, Saito Y, et al. Efficacy of primary silicone oil tamponade for the treatment of retinal detachment caused by macular hole in high myopia. Am J Ophthalmol 2011;151:148-55.

6 Meng L, Wei W, Li Y, et al. Treatment of retinal detachment secondary to macular hole in highly myopic eyes: pars plana vitrectomy with internal limiting membrane peel and silicone oil tamponade. Retina 2014;34:470-6.

7 Cheng SF, Yang CH, Lee $\mathrm{CH}$, et al. Anatomical and functional outcome of surgery of primary rhegmatogenous retinal detachment in high myopic eyes. Eye 2008;22:70-6.

8 Rizzo S, Tartaro R, Barca F, et al. Autologous internal limiting membrane fragment transplantation for rhegmatogenous retinal detachment due to paravascular or juxtapapillary retinal breaks over patchy chorioretinal atrophy in pathologic myopia. Retina 2018:38:198-202.

9 Kumase F, Morizane Y, Kimura S, et al. Autologous internal limiting membrane transplants successfully close a large parafoveal retinal hole. Acta Med Okayama 2017;71:255-7.

10 Okuda T, Higashide T, Kobayashi K, et al. Macular hole closure over residual subretinal fluid by an inverted internal limiting membrane flap technique in patients with macular hole retinal detachment in high myopia. Retin Cases Brief Rep 2016;10:140-4.

11 Gilmartin B, Nagra M, Logan NS. Shape of the posterior vitreous chamber in human emmetropia and myopia. Invest Ophthalmo/ Vis Sci 2013;54:7240-51.

12 Ohno-Matsui K, Kawasaki R, Jonas JB, et al. International photographic classification and grading system for myopic maculopathy. Am J Ophthalmol 2015;159:877-83.

13 Huang Y, Huang W, Ng DSC, et al. Risk factors for development of macular hole retinal detachment after pars plana vitrectomy for pathologic myopic foveoschisis. Retina 2017;37:1049-54
14 Sayanagi K, Ikuno Y, Tano Y. Tractional internal limiting membrane detachment in highly myopic eyes. Am J Ophthalmol 2006;142:850-2.

15 Chaker N, Mghaieth F, Chebil A. Management of rhegmatogenous retinal detachment with unseen breaks: about 50 cases. Bull Soc Belge Ophtalmol 2013;322:111-5.

16 De Novelli FJ, Preti RC, Ribeiro Monteiro ML, et al. Autologous internal limiting membrane fragment transplantation for large, chronic, and refractory macular holes. Ophthalmic Res 2015;55:45-52.

17 Paques M, Chastang C, Mathis A, et al. Effect of autologous platelet concentrate in surgery for idiopathic macular hole: results of a multicenter, double-masked, randomized trial. Platelets in Macular Hole Surgery Group. Ophthalmology 1999:106:932-8.

18 Thompson JT, Smiddy WE, Williams GA, et al. Comparison of recombinant transforming growth factor-beta-2 and placebo as an adjunctive agent for macular hole surgery. Ophthalmology 1998;105:700-6.

19 Michalewska Z, Michalewski J, Adelman RA, et al. Inverted internal limiting membrane flap technique for large macular holes. Ophthalmology 2010;117:2018-25.

20 Mahalingam P, Sambhav K. Surgical outcomes of inverted internal limiting membrane flap technique for large macular hole. Indian J Ophthalmol 2013:61:601-3.

21 Michalewska Z, Michalewski J, Dulczewska-Cichecka K, et al. Inverted internal limiting membrane flap technique for surgical repair of myopic macular holes. Retina 2014;34:664-9.

22 Kuriyama S, Hayashi $\mathrm{H}$, Jingami $\mathrm{Y}$, et al. Efficacy of inverted internal limiting membrane flap technique for the treatment of macular hole in high myopia. Am J Ophthalmol 2013;156:125-31.

23 Matsumura T, Takamura Y, Tomomatsu T, et al. Comparison of the inverted internal limiting membrane flap technique and the internal limiting membrane peeling for macular hole with retinal detachment. PLoS One 2016;11:e0165068.

24 Chen SN, Yang CM. Lens capsular flap transplantation in the management of refractory macular hole from multiple etiologies. Retina 2016;36:163-70.

25 Grewal DS, Mahmoud TH. Autologous neurosensory retinal free flap for closure of refractory myopic macular holes. JAMA Ophthalmol 2016;134:229-30. 